\title{
Effects of Aging on Glucose-mediated Glucose Disposal and Glucose Transport
}

\author{
R. I. Fink, P. Wallace, and J. M. Olefsky \\ Department of Medicine and Research Service, Veterans Administration Medical Center and the University of California, \\ San Diego, California 92161
}

\begin{abstract}
To assess the effects of aging on glucose-mediated glucose disposal and glucose transport, glucose disposal rates were measured in 10 nonelderly ( $32 \pm 4 \mathrm{yr})$ and 11 elderly (64 $\pm 4 \mathrm{yr})$ subjects at five different plasma glucose concentrations. Glucose disposal was decreased by 30-35\% in the elderly at each level of glycemia (100-350 $\mathrm{mg} / \mathrm{dl})$ in the presence of similar levels of hyperinsulinemia $(\sim 100 \mu \mathrm{U} / \mathrm{ml})$, and the $50 \%$ effective concentration $\left(\mathrm{EC}_{50}\right)$ was similar in both the nonelderly $(100 \pm 9)$ and elderly $(103 \pm 5 \mathrm{mg} / \mathrm{dl})$. The Michaelis constant $\left(K_{\mathrm{m}}\right)$ of 3-O-methyl glucose transport in adipocytes was unchanged with aging $(3.8 \pm 0.5$ vs. $3.2 \pm 0.2 \mathrm{mM}$ ) while the maximum velocity of insulin stimulated transport was reduced by $34 \%$ in the elderly $(8.3 \pm 1.3 \mathrm{vs}$. 12.6 $\pm 1.5 \mathrm{pmol} / 5 \times 10^{4}$ cells per $\left.\mathrm{s}, P<0.05\right)$. The insulin resistance of aging is therefore due to a reduction in the capacity of the glucose uptake system, while the affinity of glucose utilization ( $\left(E C_{s 0}\right.$ and $K_{m}$ ) is unchanged. This supports the hypothesis that a reduction in the number of glucose transport and metabolic units occurs with aging, but that each unit functions normally.
\end{abstract}

\section{Introduction}

Glucose intolerance is a well recognized characteristic of human aging (1). This glucose intolerance is generally accompanied by hyperinsulinemia, indicating an insulin-resistant state. Indeed, evidence in favor of insulin resistance was presented some 40 years ago by Himsworth and Kerr, who demonstrated a decrease in insulin sensitivity with aging using an oral glucose tolerance test with a simultaneous intravenous insulin injection (2). These conclusions have been substantiated over the years, primarily with the advent of the glucose clamp technique, which has enabled us to not only establish the existence of insulin resistance with aging, but also to quantitate the severity of the resistant state and to gain insights as to its mechanisms (3-6). Recent in vivo data using the euglycemic glucose clamp technique to construct insulin dose-response curves for glucose disposal have indicated that insulin resistance in aging manifests itself as a rightward shift in the insulin dose-response curve with maximal responsiveness ranging from normal to markedly decreased, depending on the degree of glucose intolerance present in the elderly $(4,5)$. When insulin binding to either adipocytes or monocytes has been simultaneously measured in these studies,

This work was presented in part at the Annual Meeting of the American Diabetes Association, Baltimore, MD, 13-18 June 1985.

Address correspondence and reprint requests to Dr. Fink, Veterans Administration Medical Center, 3350 La Jolla Village Dr. (111 G), La Jolla, CA 92161.

Received for publication 21 October 1985 and in revised form 20 February 1986.

The Journal of Clinical Investigation, Inc.

Volume 77, June 1986, 2034-2041 no changes could be demonstrated in the aged. Since insulin resistance exists in the face of normal insulin binding, the probable locus of the insulin resistance must reside at a postbinding step. We and others have demonstrated a decrease in glucose transport activity in adipocytes from elderly subjects $(7,8)$ that is consistent with this formulation. Furthermore, more distal defects in intracellular metabolism involving decreased maximal glucose oxidation have also recently been identified with aging (9). All these studies, therefore, point to a postbinding defect in insulin action that occurs with aging. However, they do not distinguish between the effects of insulin on the processes of glucose metabolism and a defect in the glucose metabolism processes themselves.

In an effort to further elucidate the mechanisms of insulin resistance in aging, we have utilized the glucose clamp technique to study insulin-stimulated glucose disposal rates over a wide range of glucose concentrations in younger and older individuals. The purpose of the study was to examine the in vivo kinetic characteristics of glucose utilization by measuring the effects of glucose in stimulating its own disposal and thus to determine whether there existed alterations in the efficiency or capacity of glucose disposal with aging. In addition, we have examined the kinetic characteristics of the glucose transport system in adipocytes from the same population to determine the maximum velocity $\left(V_{\max }\right)$ and the Michaelis constant $\left(K_{\mathrm{m}}\right)$ of glucose transport in young and old and to provide in vivo and in vitro correlates.

\section{Methods}

\section{Materials}

$\left[3-{ }^{3} \mathrm{H}\right]$ glucose was purchased from New England Nuclear (Boston, MA). Bovine serum albumin (fraction V) was obtained from Boehringer Mannheim Biochemicals (Indianapolis, IN). Collagenase was purchased from Cappel/Worthington Life Science (Malvern, PA). Cyclic somatostatin (SRIF)' ${ }^{1}$ was purchased from Bachem Corp. (Torrance, CA).

\section{Subjects}

The study group included a total of 21 nonobese healthy volunteers, divided into two groups on the basis of age. The nonelderly group consisted of 10 men aged $26-40 \mathrm{yr}$ (mean $\pm \mathrm{SD}, 32 \pm 4 \mathrm{yr}$ ) and the elderly group consisted of 10 men and 1 woman aged 60-70 yr (mean $\pm S D$, $64 \pm 4 \mathrm{yr}$ ). All subjects were within $20 \%$ of ideal body weight, based on the Metropolitan Life Insurance Tables. They were in good general health and had no evidence of renal, hepatic, or cardiac dysfunction. None of the subjects was taking any medication during the study, with the exception of iron supplementation. After informed consent was obtained, subjects were admitted to the Special Diagnostic and Treatment Unit of the San Diego Veterans Administration Medical Center. Daily carbohydrate intake as determined by dietician-obtained histories was $150 \mathrm{~g}$

1. Abbreviations used in this paper: ANOVA, analysis of variance; $\mathrm{EC}_{50}$, $50 \%$ effective concentration; LBM, lean body mass; MCR, metabolic clearance rate of glucose; NIMGU, non-insulin-mediated glucose uptake; SRIF; somatostatin. 
in both nonelderly and elderly subjects in the week before the studies. Subjects were weighed daily and calories adjusted to maintain initial weight throughout the study. The diet contained $45 \%$ carbohydrate, $35 \%$ fat, and $20 \%$ protein. The clinical and metabolic characteristics of the subjects are summarized in Table $I$.

An oral glucose tolerance test $(75 \mathrm{~g})$ was performed before participation of each subject in the experimental protocol. Six of the elderly group and one of the nonelderly group had 2-h plasma glucose values greater than $140 \mathrm{mg} / \mathrm{dl}$. Three of the six elderly subjects had impaired glucose tolerance while the other three and the one nonelderly individual had nondiagnostic glucose tolerance tests as defined by the National Diabetes Data Group (10). As a whole, the elderly group was significantly more glucose intolerant than the nonelderly group as indicated by the 2-h glucose values.

Total kilograms of fat was calculated in all subjects according to the formula of Rowe et al. (5) by measuring abdominal and triceps skin fold thickness, abdominal circumference, and 24-h urinary creatinine. Skin folds were measured with the use of Lange skin fold calipers. The kilograms of lean body mass (LBM) were then calculated as total weight minus the kilograms of fat.

\section{Study protocol}

Glucose clamp studies. The glucose clamp technique was used as previously described (4). Insulin was infused in a primed continuous fashion at a rate of $40 \mathrm{mU} / \mathrm{M}^{2}$ per min in all of the studies. The plasma glucose was clamped at five different levels of glycemia in each patient, and the studies were all carried out on separate days. Thus, five separate glucose clamps were performed in each subject. The goal plasma glucose concentrations were $100,150,200,250$, and $350 \mathrm{mg} / \mathrm{dl}$. During the hyperglycemic studies, glucose was infused in a priming dose to increase the plasma glucose to the desired level in a 10-min period, according to a modification of the protocol of DeFronzo et al. (11). SRIF was infused throughout each of the studies at a rate of $600 \mu \mathrm{g} / \mathrm{h}$, to suppress endogenous insulin secretion. $\left[3-{ }^{3} \mathrm{H}\right]$ glucose was infused in a primed continuous fashion only during the 100 and $150 \mathrm{mg} / \mathrm{dl}$ studies. $30 \mu \mathrm{Ci}$ of [3${ }^{3} \mathrm{H}$ ]glucose was injected as a bolus, followed by a continuous infusion at the rate of $0.6 \mu \mathrm{Ci} / \mathrm{min}$. It was not necessary to infuse $\left[3-{ }^{3} \mathrm{H}\right]$ glucose during the hyperglycemic studies, since under the conditions of our protocol, i.e., hyperinsulinemia, hyperglycemia, and glucagon deficiency due to the infusion of SRIF, hepatic glucose output is completely suppressed. In fact, even during the studies done at the lowest plasma glucose concentration of 100 and $150 \mathrm{mg} / \mathrm{dl}$, hepatic glucose output was completely suppressed in both age groups.

After the initiation of the glucose and insulin infusions, the desired level of glycemia was maintained for at least $180 \mathrm{~min}$, or until the glucose infusion rate had not changed by more than $\pm 10 \%$ for $60 \mathrm{~min}$. The mean length for each study was $194 \mathrm{~min}$ with a range of 180-260 min. There was no difference between the two groups in the length of study (194 \pm 5 min vs. $194 \pm 2 \mathrm{~min}$ in the nonelderly and elderly, respectively). The glucose disposal rates for the last three 20-min intervals of each study were measured and used as the datum point for that particular study.

Table I. Metabolic Characteristics of Nonelderly and Elderly Groups

\begin{tabular}{lccl}
\hline & $\begin{array}{c}\text { Nonelderly } \\
(n=10)\end{array}$ & $\begin{array}{c}\text { Elderly } \\
(n=11)\end{array}$ & \\
\hline Age $(y r)$ & $32 \pm 2$ & $65 \pm 2$ & \\
Age range & $21-40$ & $60-70$ & \\
BMI $\left(k g / M^{2}\right)$ & $23.5 \pm 0.5$ & $23.5 \pm 1.0$ & NS \\
Fat cell size $(p l)$ & $361 \pm 44$ & $419 \pm 40$ & NS \\
Fasting glucose $(m g / d l)$ & $93 \pm 1$ & $94 \pm 2$ & NS \\
Fasting insulin $(\mu U / m l)$ & $10 \pm 1$ & $12 \pm 1$ & NS \\
2-hour OGTT glucose $(m g / d l)$ & $118 \pm 4$ & $144 \pm 8$ & $P<0.01$
\end{tabular}

BMI, body mass institute; OGTT, oral glucose tolerance test.
Urinary glucose was measured during the studies and was subtracted from the glucose infusion rate to give the true glucose disposal rate.

Glucose transport studies. Adipose tissue was obtained from the lower abdominal region after a 14-h overnight fast, as previously described (12) and glucose transport was assayed by measuring initial rates of 3-Omethyl glucose influx according to a modification (13) of the method of Whitesell and Gliemann (14). The substrate, 3-O-methyl-D-[U${ }^{14} \mathrm{C}$ glucose $(0.4 \mu \mathrm{Ci} /$ tube), was added to unlabeled 3-O-methyl glucose to give the final desired concentration as indicated. A $40 \%$ cell suspension was preincubated with and without $100 \mathrm{ng} / \mathrm{ml}$ insulin for $30 \mathrm{~min}$. The reaction was started by the addition of $50 \mu$ l of the cell suspension to 20 $\mu l$ of the substrate and subsequently terminated at time intervals ranging from $20 \mathrm{~s}$ to $3.5 \mathrm{~min}$ in the basal state, and from 10 to $60 \mathrm{~s}$ in the insulinstimulated state, to ensure that initial uptake of 3-O-methyl glucose was being measured at all glucose concentrations. The reaction was terminated by the rapid addition of $400 \mu \mathrm{l}$ of $0.1 \mathrm{mM}$ phloretin. Aliquots were transferred to $550-\mu \mathrm{l}$ microfuge tubes and centrifuged over silicone oil, after which the cell-associated radioactivity was counted. The portion of cellular uptake due to diffusion and trapping of the label in the extracellular water space was measured by performing parallel reactions with the cell suspension added directly to a mixture of phloretin and substrate. All values of transport were corrected for the trapping and extracellular water space and the data expressed as picomoles 3-O-methylglucose transport $/ 5 \times 10^{4}$ cells per second. Adipocyte counts were performed according to a modification of method III of Hirsch and Gallian (15). Cell sizing was determined as previously described (16).

Analytical methods. Serum insulin levels were measured by a doubleantibody radioimmunoassay according to the method of Desbuquois and Aurbach (17). C peptide levels were measured courtesy of Dr. A. Rubenstein at the University of Chicago, Chicago, IL, by a previously described assay (18).

Data analysis. Data presented represent the mean \pm SEM. Statistical analysis employed two-tailed paired and unpaired Student's $t$ tests as indicated. Analysis of variance (ANOVA) for repeated measures was used to test for differences between groups and for changes over dose (for studies of glucose transport and glucose disposal rates). Correlation coefficients were determined using linear regression analysis. Statistical analyses were performed on a Digital PDP 11/24 computer (Digital Equipment Corp., Marlboro, MA) using the CLINFO data base management and analysis program (Bolt, Beraneck, and Newman, Inc., Cambridge, MA).

\section{Results}

Glucose clamp studies: plasma glucose, insulin, and C peptide (Table II): The goal glucose levels were attained in both groups with a coefficient of variation of $<5 \%$ for each of the studies performed. Steady state serum insulin levels were similar (100 $\mu \mathrm{U} / \mathrm{ml})$ in both the elderly and nonelderly group at each level of glycemia, with the sole exception of the elderly group studied at a plasma glucose concentration of $350 \mathrm{mg} / \mathrm{dl}$ where the serum insulin level was somewhat higher $(124 \pm 6 \mu \mathrm{U} / \mathrm{ml})$ compared with the nonelderly group $(109 \pm 6 \mu \mathrm{U} / \mathrm{ml}, P<0.05)$. Despite the increasing plasma glucose levels attained during the clamp studies, endogenous insulin secretion remained suppressed due to the SRIF infusion. Even at a glucose concentration of $\mathbf{3 5 0}$ $\mathrm{mg} / \mathrm{dl}, \mathrm{C}$ peptide was suppressed by $40 \pm 11 \%$ in the nonelderly and $41 \pm 9 \%$ in the elderly group (Table II). Absolute basal C peptide values were similar in both groups as well $(0.35 \pm .04$ vs. $0.38 \pm .03 \mathrm{pmol} / \mathrm{ml}$ in the nonelderly and elderly, respectively) and no difference was observed in the ability of SRIF to inhibit endogenous insulin release in the two age groups. In both the elderly and nonelderly, however, SRIF resulted in a greater suppression of $C$ peptide at lower glucose levels of 100 and 150 $\mathrm{mg} / \mathrm{dl}$ compared with the hyperglycemic levels of 250 and 350 $\mathrm{mg} / \mathrm{dl}$ (Table II). 


\begin{tabular}{|c|c|c|c|c|c|}
\hline & \multicolumn{5}{|c|}{ Goal glucose } \\
\hline & $100 \mathrm{mg} / \mathrm{dl}$ & $150 \mathrm{mg} / \mathrm{dl}$ & $200 \mathrm{mg} / \mathrm{dl}$ & $250 \mathrm{mg} / \mathrm{dl}$ & $350 \mathrm{mg} / \mathrm{dl}$ \\
\hline \multicolumn{6}{|c|}{ Plasma glucose $(m g / d l)$} \\
\hline Nonelderly & $100 \pm 1$ & $150 \pm 1$ & $200 \pm 1$ & $250 \pm 1$ & $350 \pm 1$ \\
\hline Elderly & $99 \pm 1$ & $149 \pm 1$ & $201 \pm 1$ & $249 \pm 1$ & $349 \pm 1$ \\
\hline \multicolumn{6}{|c|}{ Serum Insulin $(\mu U / m l)$} \\
\hline Nonelderly & $97 \pm 5$ & $96 \pm 5$ & $106 \pm 5$ & $93 \pm 5$ & $109 \pm 6$ \\
\hline Elderly & $102 \pm 4$ & $116 \pm 9$ & $108 \pm 7$ & $104 \pm 6$ & $124 \pm 6^{*}$ \\
\hline \multicolumn{6}{|c|}{$\begin{array}{l}\text { C Peptide Suppression during glucose clamp studies } \\
\text { (\%) }\end{array}$} \\
\hline Nonelderly & $95 \pm 1$ & $92 \pm 1$ & $84 \pm 3$ & $66 \pm 9$ & $40 \pm 11$ \\
\hline Elderly & $93 \pm 1$ & $92 \pm 1$ & $90 \pm 1$ & $72 \pm 4$ & $41 \pm 9$ \\
\hline
\end{tabular}

* $P<0.05$ compared with nonelderly at $350 \mathrm{mg} / \mathrm{dl} . \quad P<0.05$ compared with elderly at 100,200 , and $250 \mathrm{mg} / \mathrm{dl}$.

Glucose disposal rates. Glucose disposal rates were significantly decreased by $30-35 \%$ in the elderly group, compared with the nonelderly group, at all steady state plasma glucose concentrations, ranging from 100 to $350 \mathrm{mg} / \mathrm{dl},(P<0.05, F=9.93$, ANOVA) (Fig. $1 A$, Table III). This indicates that the insulin resistance of aging is expressed equally at all glucose levels and that it is the maximal capacity for glucose metabolism which is impaired. The decrease in glucose uptake in the elderly was similarly apparent when the data were analyzed on a per kilogram LBM basis (Fig. $1 B$, Table III, $P<0.05, F=6.75$, ANOVA). Hepatic glucose output was completely and equally suppressed by $100 \%$ in both age groups during the studies done at plasma glucose concentrations of 100 and $150 \mathrm{mg} / \mathrm{dl}$. Because of this complete suppression at lower glucose concentrations, [3${ }^{3} \mathrm{H}$ ]glucose was not infused during studies done at higher plasma glucose levels of 200, 250, and $350 \mathrm{mg} / \mathrm{dl}$.

Glucose utilization increased significantly $(P<0.05)$ in both the nonelderly and elderly subjects when the plasma glucose concentration was increased from 100 to $250 \mathrm{mg} / \mathrm{dl}$ during the $40 \mathrm{mU} / \mathrm{M}^{2}$ per min insulin infusions. However, increasing the glucose concentration from 250 to $350 \mathrm{mg} / \mathrm{dl}$ resulted in no significant increase in glucose disposal rates in both groups $(15.2 \pm 1.6 \mathrm{vs} .16 .4 \pm 1.5 \mathrm{mg} / \mathrm{kg}$ per $\mathrm{min}$ in the nonelderly group and $10.9 \pm 1.0 \mathrm{vs.} 11.3 \pm 0.9 \mathrm{mg} / \mathrm{kg}$ per $\mathrm{min}$ in the elderly group). This indicates that glucose utilization was almost totally saturated at a glucose level of $250 \mathrm{mg} / \mathrm{dl}$ during physiological hyperinsulinemia.

In order to more closely examine the ability of glucose to increase total glucose disposal; and to determine if aging resulted in an impaired ability of an increasing glucose concentration to increase glucose utilization, the glucose disposal rates were analyzed as a percentage of the maximal glucose disposal and the change in the percent increase in glucose disposal per change in plasma glucose (slope) (19) was examined in both groups (Fig. 2). This relationship was evaluated over the glucose concentrations where glucose uptake increased in a fairly linear fashion, i.e., from 100 to $250 \mathrm{mg} / \mathrm{dl}$. This was confirmed by least squares linear regression analysis and indicated that the slope did not differ significantly between the nonelderly $(r=0.91 \pm 0.03$, slope $=0.25 \pm 0.03)$ and elderly groups $(r=0.90 \pm 0.04$, slope $=0.26 \pm 0.03, P=\mathrm{NS}$ ). The similar effectiveness of glucose in increasing glucose uptake in both the nonelderly and elderly subjects is further illustrated by the plasma glucose concentration
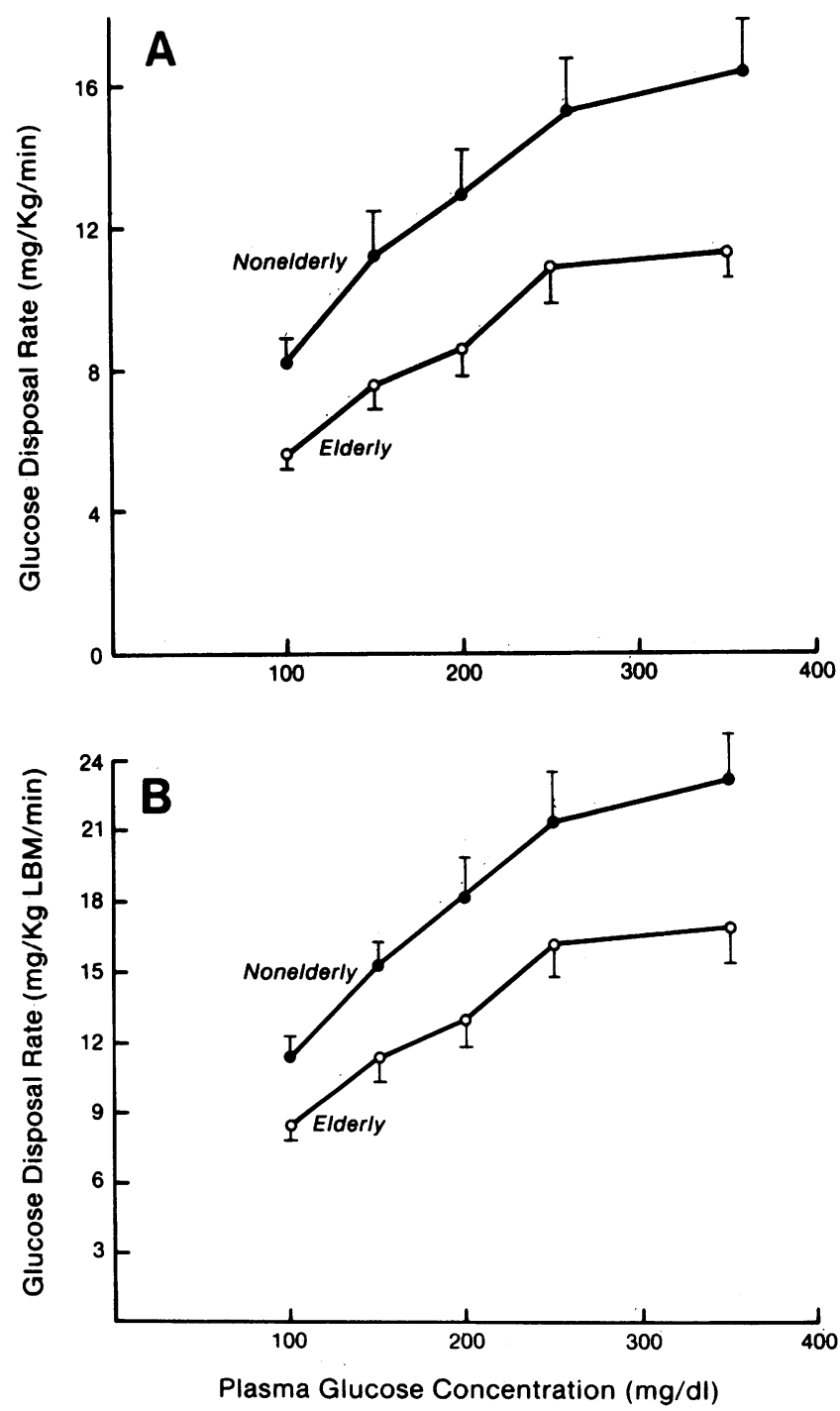

Figure 1. (A) Glucose disposal rates (milligram per kilogram per minute) at plasma glucose concentrations of $100,150,200,250$, and 350 $\mathrm{mg} / \mathrm{dl}$ during insulin infusion rates of $40 \mathrm{mU} / \mathrm{M}^{2}$ per min in nonelderly (๑) and elderly $(0)$ subjects. (B) Glucose disposal rates expressed as milligram per kilogram LBM per minute in nonelderly (๑) and elderly $(0)$ subjects. 


\begin{tabular}{|c|c|c|c|c|c|}
\hline $\begin{array}{l}\text { Glucose disposal } \\
\text { rate }\end{array}$ & $100 \mathrm{mg} / \mathrm{dl}$ & $150 \mathrm{mg} / \mathrm{dl}$ & $200 \mathrm{mg} / \mathrm{dl}$ & $250 \mathrm{mg} / \mathrm{dl}$ & $350 \mathrm{mg} / \mathrm{dl}$ \\
\hline \multicolumn{6}{|l|}{$(\mathrm{mg} / \mathrm{kg} / \mathrm{min})$} \\
\hline Nonelderly & $8.2 \pm 0.8$ & $11.2 \pm 1.3$ & $12.9 \pm 1.3$ & $15.2 \pm 1.6$ & $16.4 \pm 1.5 \ddagger$ \\
\hline Elderly & $5.7 \pm 0.4^{*}$ & $7.6 \pm 0.7^{*}$ & $8.6 \pm 0.7^{*}$ & $10.9 \pm 1.0^{*}$ & $11.3 \pm 0.9 * \S$ \\
\hline \multicolumn{6}{|c|}{$(\mathrm{mg} / \mathrm{kg} \mathrm{LBM} / \mathrm{min})$} \\
\hline Nonelderly & $11.4 \pm 1.0$ & $15.5 \pm 1.6$ & $18.1 \pm 1.8$ & $21.3 \pm 2.2$ & $23.1 \pm 2.0 \ddagger$ \\
\hline Elderly & $8.5 \pm 0.7^{*}$ & $11.3 \pm 1.0^{*}$ & $13.0 \pm 1.2^{*}$ & $16.2 \pm 1.6$ & $16.9 \pm 1.5^{*} \S$ \\
\hline
\end{tabular}

$* P<0.05$ for differences between elderly and nonelderly subjects. $¥ P=\mathrm{NS}$ compared with nonelderly at $250 \mathrm{mg} / \mathrm{dl}$. $\$ P=\mathrm{NS}$ compared with elderly at $250 \mathrm{mg} / \mathrm{dl}$.

at which half the maximal glucose disposal rate was observed $\left(E_{50}\right)$. This was determined for each individual based on a plot of the percent of maximal glucose disposal versus plasma glucose concentrations. These values (Fig. 2) were virtually identical in the two groups, $100 \pm 9 \mathrm{mg} / \mathrm{dl}$ in the nonelderly subjects and $103 \pm 5 \mathrm{mg} / \mathrm{dl}$ in the elderly subjects $(P=\mathrm{NS})$. As predicted by the similar $\mathrm{EC}_{50}$ values in the two groups, there was no significant relationship observed between the $\mathrm{EC}_{50}$ and the 2-h plasma glucose value during the oral glucose tolerance test $(r=0.18$, nonelderly; $r=-0.27$, elderly; $P=\mathrm{NS}$ ) or between the slope as derived in Fig. 2 and the 2-h glucose value ( $r=-0.14$, nonelderly; $r=0.21$, elderly; $P=\mathrm{NS}$ ).

The glucose disposal curves were also analyzed using the assumption that in vivo glucose uptake follows Michaelis-Menten kinetics as suggested by Gottesman et al. (20). Eadie-Hofstee plots generated straight lines with similar $K_{\mathrm{m}}$ values of 296 \pm 54 vs. $296 \pm 25 \mathrm{mg} / \mathrm{dl}$ but with a $26 \%$ reduction in $V_{\max }$ in the elderly (21.9 \pm 2.1 vs. $29.4 \pm 3.8 \mathrm{mg} / \mathrm{kg}$ per $\min , P<0.05)$.

Adipocyte glucose transport. (Fig. 3) Basal rates of glucose transport were similar in the nonelderly and elderly subjects at all glucose concentrations ranging from 0.1 to $50 \mathrm{mM}$. Insulin, however, resulted in a greater stimulation of glucose transport in the nonelderly compared with the elderly $(P<0.05, F=5.02$, ANOVA). Since glucose transport follows Michaelis-Menton kinetics, the data were analyzed by Eadie-Hofstee plots in order to determine the $K_{\mathrm{m}}$ and $V_{\max }$ of glucose transport in each group (Fig. 4). In the basal state, the $K_{\mathrm{m}}$ and $V_{\max }$ of glucose transport were not significantly different in the nonelderly $\left(K_{\mathrm{m}}=3.1 \pm 0.2\right.$

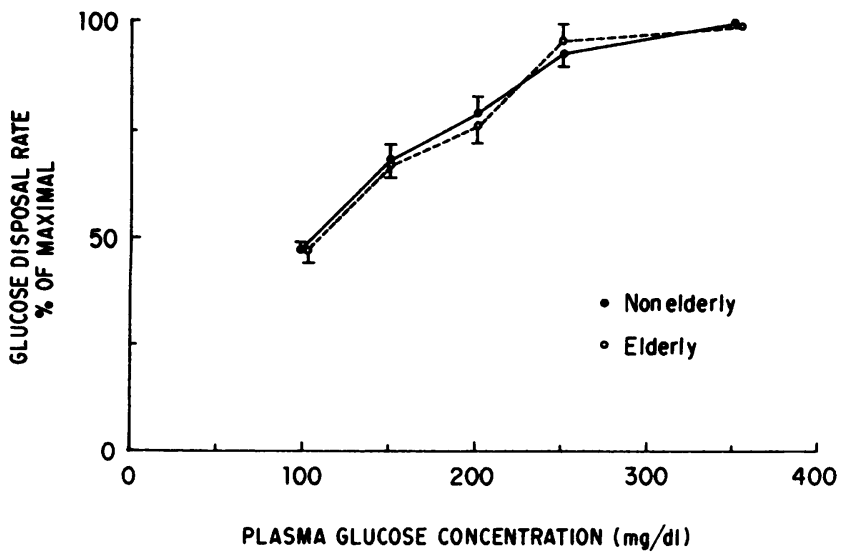

Figure 2. Glucose disposal rates expressed as a percentage of maximal glucose disposal in nonelderly $(\bullet)$ and elderly (o) subjects.
$\mathrm{mM}, V_{\max }=5.0 \pm 0.6 \mathrm{pmol} / 5 \times 10^{4}$ cells per s) compared with the elderly $\left(K_{\mathrm{m}}=3.6 \pm 0.3 \mathrm{mM}, V_{\max }=4.1 \pm 0.5 \mathrm{pmol} / 5 \times 10^{4}\right.$ cells per s). Insulin increased the $V_{\max }$ of glucose transport without changing the $K_{\mathrm{m}}$ in both groups. Therefore, in the presence of insulin, the decrease in glucose transport in the elderly group could be entirely accounted for by the $34 \%$ decrease in $V_{\max }$ (12.6 \pm 1.5 vs. $8.3 \pm 1.3 \mathrm{pmol} / 5 \times 10^{4}$ cells per s, $\left.P<0.05\right)$ (Table IV). In addition, the effect of insulin to stimulate glucose transport was decreased in the fat cells from the elderly with a $20 \%$ reduction in the fold insulin stimulation (2.5-fold increase in the nonelderly compared with a twofold increase in the elderly). Since cell size was somewhat larger in the elderly (Table I), this reduction in the $V_{\max }$ of glucose transport is even more apparent when the data are expressed on a per cell surface area basis, rather than per cell number. In the basal state, the $V_{\max }$ of glucose transport was decreased by $28 \%$ in the elderly group, although this difference did not quite achieve statistical significance (6.2 vs. $8.6 \mathrm{pmol} / 2 \times 10^{9} \mu^{2}$ per s, $P=0.07$ in the elderly and nonelderly, respectively). In the presence of insulin, however a $40 \%$ reduction in the $V_{\max }$ of glucose transport was observed in the elderly $\left(13.2 \pm 2.5\right.$ vs. $21.2 \pm 2.6 \mathrm{pmol} / 2 \times 10^{9} \mu^{2}$ per s, $P<0.05$ in the elderly and nonelderly, respectively).

\section{Discussion}

We have previously found that aging is associated with insulin resistance using euglycemic clamps across the dose-response

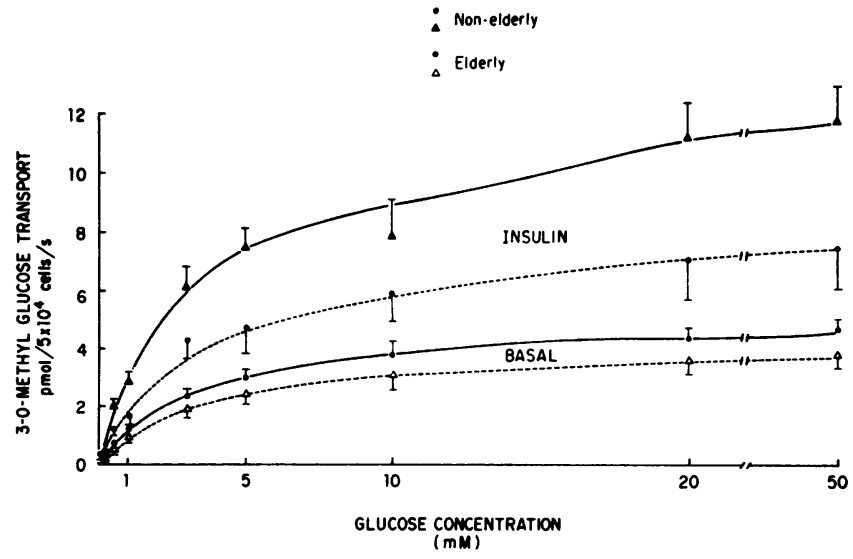

Figure 3. 3-O-methyl glucose transport in adipocytes from nonelderly $(\bullet, \Delta)$ and elderly $(0, \Delta)$ subjects in the basal state and in the presence of $100 \mathrm{ng} / \mathrm{ml}$ insulin. 


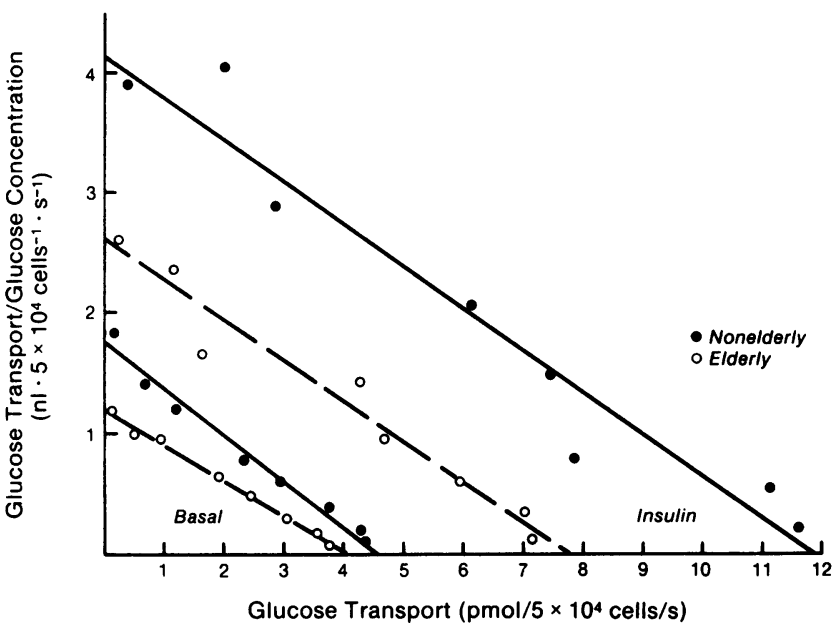

Figure 4. Kinetic characteristics of 3-O-methyl glucose transport in adipocytes from nonelderly (๑) and elderly (0) subjects. Eadie-Hofstee plot of the data in Fig. 3 in the basal state and in the presence of 100 $\mathrm{ng} / \mathrm{ml}$ insulin.

curve for insulin for a single glucose concentration (4). Overall glucose disposal encompasses the processes of glucose transport and metabolism and the effects of insulin on these processes. The presence of insulin resistance at various insulin concentrations at a single glucose concentration does not, however, distinguish between the effects of insulin on the glucose metabolism processes and a defect in the glucose metabolism processes themselves. One way to approach this problem is to study insulin stimulation of glucose disposal across a range of plasma glucose concentrations at a fixed insulin concentration. Increasing the plasma glucose concentration leads to increased rates of glucose disposal due to the mass action effectiveness of glucose in in creasing flux through the glucose transport system. Therefore, by studying insulin-stimulated glucose disposal across a range of glucose concentrations, one can distinguish between abnormalities of the glucose transport/glucose utilization system per se and insulin action on this system.

The results of our study indicate that the affinity of glucose utilization, as measured by the percent increment in glucose disposal rate per increment in plasma glucose concentration (slope), is the same in both age groups, implying that the similar reduction in glucose disposal observed in the elderly at all plasma glucose concentrations is not due to an impaired affinity of the glucose transport/metabolism units for glucose, but rather due to a reduction in the number of functioning units available. This

Table IV. Kinetic Characteristics of Glucose Transport

\begin{tabular}{lrl}
\hline & Nonelderly & Elderly \\
\hline $\mathrm{K}_{\mathrm{m}}(m M)$ & & \\
$\quad$ Basal & $3.1 \pm 0.2$ & $3.6 \pm 0.3$ \\
$\quad$ Insulin & $3.2 \pm 0.2$ & $3.8 \pm 0.5$ \\
$\mathrm{~V}_{\max }\left(\right.$ pmol $/ 5 \times 10^{4}$ & & \\
$\quad$ cells per $s)$ & & \\
$\quad$ Basal & $5.0 \pm 0.6$ & $4.1 \pm 0.5$ \\
$\quad$ Insulin & $12.6 \pm 1.5$ & $8.3 \pm 1.3 \quad P<0.05$
\end{tabular}

conclusion is supported by the in vivo data, which demonstrate a 30-35\% decrease in glucose disposal rates in the elderly at all levels of glycemia, ranging from $100-350 \mathrm{mg} / \mathrm{dl}$. However, despite the presence of insulin resistance, the incremental change in the percent of maximal glucose disposal rate per incremental change in glucose concentration, i.e., the slope, (Fig. 2) was similar in both age groups, as was the $\mathrm{EC}_{50}$, indicating that the affinity of the glucose uptake system for glucose is unaltered with aging. These in vivo findings are supported by the in vitro data, which indicate that the affinity of glucose transport as measured by the $K_{\mathrm{m}}$ is equal in both age groups. Since the functional integrity of the glucose transport system as measured by its $K_{\mathrm{m}}$ and the functional integrity of the glucose utilization system as measured by incremental glucose uptake is similar in both age groups, it follows that the affinity of glucose transport for total body glucose utilization must be normal.

Our results further indicate that although the affinity of in vivo glucose utilization is normal with age, there is a reduction in the maximal capacity of glucose utilization as demonstrated by the $30-35 \%$ reduction in glucose disposal rates at all glucose concentrations studied. This reduction in maximal capacity indicates that a decrease in the number of glucose transport/metabolic units exists. Once again, the in vitro data support this conclusion, since the maximal capacity of glucose transport, as reflected in the $V_{\max }$, was reduced by $34 \%$ in the elderly group. Since insulin's ability to increase $V_{\max }$ has been shown to be due to translocation of glucose transporters from low density intracellular microsomes to the plasma membrane $(21,22)$, a decrease in $V_{\max }$ could be due to either a smaller absolute number of transporters or to decreased translocation or availability of transporters, either of which results in a decreased in vivo glucose disposal at all glucose concentrations.

Chen and her colleagues (23) recently evaluated the mechanisms of age-related glucose intolerance using the minimal model approach. They also showed that older subjects were insulin-resistant but that so-called glucose effectiveness, i.e., the increase in fractional disappearance of glucose per unit increase in glucose, was unchanged with aging. Our results are in agreement with these data, and indicate that the effect of increasing glucose concentrations to increase glucose uptake is not decreased in the glucose-intolerant aged population both at basal serum insulin levels (23) and at serum insulin levels of about 100 $\mu \mathrm{U} / \mathrm{ml}$.

Documenting the effects of aging per se to influence insulin action and glucose metabolism is fraught with the difficulties of separating out age-related variables such as obesity, physical activity, and caloric intake, each known to independently alter insulin action. It is unlikely, however, that the differences between the nonelderly subjects and elderly subjects could be entirely accounted for by these factors. Firstly, LBM was not significantly different between the two groups, and when the data were analyzed on a per kilogram LBM basis, similar differences in glucose disposal rates between the two age groups could be seen. Secondly, fat cell size, another independent marker of obesity, was not significantly different between the nonelderly and elderly groups and, therefore, the differences in the glucose transport data could not be solely attributed to increased adiposity in the elderly. Thirdly, within age groups, and considering all glucose infusion levels, there were no statistically significant relationships between steady state glucose disposal rates and percent body fat (nonelderly, $r=-0.29, P=\mathrm{NS}$; elderly, $r$ $=+0.24, P=\mathrm{NS}$ ). Although no measurements of the degree of 
physical conditioning of the subjects were made in our study, all subjects selected were fully active and leading nonsedentary lifestyles, and none were involved in any vigorous exercise program that may have unduly affected our results. Although dietary carbohydrate intake is often reduced with aging and could result in impairment in measurements of insulin action, it is unlikely to have accounted for any significant differences in our study, since all subjects were maintained on at least $150 \mathrm{~g}$ carbohydrate in the week before studies and on a weight-maintenance isocaloric diet during the study.

All the glucose clamp studies were done with insulin infusion rates of $40 \mathrm{mU} / \mathrm{M}^{2}$ per min and in the presence of SRIF. Even with steady state plasma glucose levels of $350 \mathrm{mg} / \mathrm{dl}$, SRIF was still effective in suppressing endogenous insulin release as assessed by serum $\mathrm{C}$ peptide concentrations. The inhibition of insulin secretion was $40 \%$ compared with $92 \%$ at steady state plasma glucose levels of $150 \mathrm{mg} / \mathrm{dl}$, but importantly, no breakthrough of endogenous insulin secretion occurred under these hyperglycemic conditions. Serum insulin levels were therefore comparable in both age groups at all glucose concentrations with the exception of a small $14 \%$ increased steady state insulin concentration in the elderly group studied at a plasma glucose concentration of $350 \mathrm{mg} / \mathrm{dl}$. This did not alter the results of the studies, since glucose disposal rates were still decreased by $30-35 \%$ in the elderly at all plasma glucose concentrations, including the studies done at $350 \mathrm{mg} / \mathrm{dl}$ where the serum insulin levels were, in fact, higher.

Each of the clamp studies was done on a separate day and in order to compare results both between and within groups it was essential that serum insulin levels be closely matched. 40 $\mathrm{mU} / \mathrm{M}^{2}$ per min insulin infusions were thus chosen, since we and others (3-5) have previously demonstrated that serum insulin concentrations of $100 \mu \mathrm{U} / \mathrm{ml}$ were attained in both younger and older subjects. A lower insulin infusion rate would have resulted in considerably higher serum insulin levels in the elderly because of the decrease in the metabolic clearance rate of insulin, which is more evident at lower insulin concentrations (24) and has been shown in prior studies (24-26).

Recently, it has been suggested that SRIF may have an independent effect in increasing peripheral glucose utilization (27). These results were demonstrated in dogs, and although there has been no confirmation of this observation in humans, it is unlikely that this would have significantly influenced our data. We have used a $600 \mu \mathrm{g} / \mathrm{h}$ dose of SRIF to ensure inhibition of insulin secretion at the higher plasma glucose levels. Even this dose, however, is only $15-20 \%$ (on a per kilogram basis) of the dose used in dog studies, which demonstrated the independent glucose lowering effect of SRIF (27). In addition, we used the same dose of SRIF for all studies regardless of the steady state plasma glucose and, therefore, valid comparisons of glucose disposal rates can be made within and between the two age groups. Finally, the magnitude of the SRIF effect would likely be quite small in relation to the total glucose disposal rates measured at hyperinsulinemia and hyperglycemia. The previously reported SRIF effect was demonstrated during basal insulin replacement (27).

SRIF inhibits not only insulin release but also growth hormone secretion and glucagon release. The deficiencies of both these hormones would have very little impact on the results of our studies for the following reasons. Glucagon has previously been shown to have no effect on peripheral glucose uptake (28) and prolonged infusions (longer than $6 \mathrm{~h}$ ) of growth hormone are necessary to demonstrate an effect on glucose uptake (29). The duration of our infusions was considerably less (3-4h) and therefore it is unlikely that we were overestimating the glucose disposal rates as a result of growth hormone deficiency.

A finding of considerable interest in our study was the abrupt saturation of glucose uptake that occurred in both age groups between glucose concentrations of 250 and $350 \mathrm{mg} / \mathrm{dl}$. Studies done at plasma glucose concentrations of $350 \mathrm{mg} / \mathrm{dl}$ resulted in an insignificant $3.7 \%$ increase in glucose disposal rate compared with studies done at glucose levels of $250 \mathrm{mg} / \mathrm{dl}$ in both age groups. The plateauing of glucose uptake that occurs at these high plasma glucose levels could be due either to saturation of glucose transport or to the emergence of a more distal postglucose transport step as the rate-limiting process for overall metabolism. If the rate-limiting step for overall glucose utilization resides at an intracellular step when the glucose concentration is raised from 250 to $350 \mathrm{mg} / \mathrm{dl}$, then this would indicate that with aging the decrease in the $V_{\max }$ of glucose transport accounts for the decrease in glucose disposal at plasma glucose concentrations between 100 and $250 \mathrm{mg} / \mathrm{dl}$, but that further intracellular defects in glucose metabolism also exist which impair overall glucose utilization when the plasma glucose level is increased above 250 $\mathrm{mg} / \mathrm{dl}$. This conclusion is based on the fact that at a plasma glucose level of $350 \mathrm{mg} / \mathrm{dl}$ overall glucose disposal rates were $31 \%$ lower in the elderly group. If intracellular glucose metabolism is rate-limiting at this rate of glucose flux, then the defect in aging must reside at an intracellular locus with a resultant decreased capacity of glucose metabolism. On the other hand, if glucose transport is still rate-limiting at a glucose concentration of $350 \mathrm{mg} / \mathrm{dl}$, then the plateauing of in vivo glucose uptake is consistent with saturation of the transport system. The decrease in glucose disposal at all glucose levels would then be due to a decrease in maximal capacity of glucose transport and a normal affinity of the glucose transport system with aging. Further studies will be necessary to distinguish between these possibilities.

It has previously been suggested by Gottesman et al. that in vivo glucose uptake could be analyzed by Michaelis-Menten kinetics and that insulin increases the $V_{\max }$ of glucose uptake without a change in the $K_{\mathrm{m}}(20)$. Glucose uptake was measured at several insulin concentrations, but at a maximal glucose concentration of only $160 \mathrm{mg} / \mathrm{dl}$, a point on the glucose dose-response curve where glucose uptake is still linear. Therefore, it was not demonstrated in that study that saturation of glucose uptake occurred, and one can question the assumption that $\mathrm{Mi}$ chaelis-Menten kinetics can be used to assess total body in vivo glucose uptake. Our data tend to cast doubt on the accuracy of this kind of analysis. Thus, when our data were analyzed using this assumption, Eadie-Hofstee plots generated straight lines with a $K_{\mathrm{m}}$ of $\sim 300 \mathrm{mg} / \mathrm{dl}$ in both groups and a $V_{\max }$ of 29 and 21 $\mathrm{mg} / \mathrm{kg}$ per min in the nonelderly and elderly groups, respectively. The $K_{\mathrm{m}}$ values are clearly much higher than the actual $\mathrm{EC}_{50}$ values calculated from the glucose dose-response curves $(\sim 100$ $\mathrm{mg} / \mathrm{dl}$ in both age groups). Additionally, the calculated $V_{\max }$ is a full twofold greater than the actual maximally measured glucose uptake at a plasma glucose concentration of $350 \mathrm{mg} / \mathrm{dl}$. There are many reasons why whole-body glucose uptake may not follow Michaelis-Menten kinetics. Firstly, there is now recent evidence to indicate that not all tissues in the body respond equally to insulin in increasing glucose uptake $(30,31)$. For example, the maximal responsiveness of rat diaphragm is fivefold greater than that of rat lung tissue (31). Secondly, differences exist even in similar tissues, such that insulin-mediated glucose uptake in 
skeletal muscle consisting primarily of oxidative fibers is substantially different from glucose uptake in glycolytic muscle (32). Therefore, differences in muscle composition between one individual and another may play a role in determining total-body glucose uptake and these different types of insulin-responsive tissue may also have different kinetics of glucose uptake. Thirdly, glucose uptake is not a homogeneous process but consists of both insulin-mediated glucose uptake and noninsulin-mediated glucose uptake (NIMGU) (33). NIMGU largely involves central nervous system glucose metabolism, and it is likely that the kinetics of glucose uptake into the central nervous system differ substantially from that in peripheral tissues; this further weakens the analysis of whole-body glucose uptake by simple MichaelisMenten kinetics. Therefore, it appears that overall glucose disposal rates are composed of several different uptake rates in different tissues and on aggregate they do not conform to Michaelis-Menten kinetics. It is probable, though, that in each individual tissue one could use this analysis to define the glucose uptake characteristics.

It has previously been shown that glucose uptake is not independent of the plasma glucose concentration and that the metabolic clearance rate of glucose (MCR) decreases with increases in glucose concentrations (34-36). Our data are consistent with this view and indicate that even when glucose utilization is linear over a range of glucose concentrations, the MCR is still falling. In the nonelderly group the MCR decreased by $26 \%$ with increasing glucose concentrations from 100 to $250 \mathrm{mg} / \mathrm{dl}$, while it fell by a similar $24 \%$ in the elderly group. The reduction in MCR occurred in the presence of insulin levels of about 100 $\mu \mathrm{U} / \mathrm{ml}$, a level at which the effectiveness of increasing glucose concentration to decrease the MCR has been shown to be minimal (37). Thus, even in the presence of hyperinsulinemia, it is clear that the saturation kinetics of glucose uptake coupled with the smaller relative contribution of NIMGU to total glucose uptake result in a decreasing MCR of glucose with increasing glucose concentrations.

In conclusion, we have evaluated the effectiveness of glucose in increasing glucose utilization in the presence of physiological hyperinsulinemia in a group of younger and older subjects. Glucose uptake is linear in both groups up to a plasma glucose of about $250 \mathrm{mg} / \mathrm{dl}$; thereafter total glucose disposal is virtually completely saturated. Glucose increases glucose uptake to a similar degree in both age groups, but at a lower total glucose disposal rate in the elderly, indicating their insulin resistance. The decrease in maximal glucose uptake with normal affinity of glucose uptake that occurs with aging is reflected in a decreased $V_{\max }$ of glucose transport activity with a normal $K_{\mathrm{m}}$ in the elderly group. These data are consistent with the possibility that a decrease in glucose transporter numbers or a lower rate of translocation of transporters, rather than an altered function of a glucose transporter unit, underlies the insulin resistance of aging. In addition, a decrease in the maximal capacity of intracellular glucose metabolism may also exist with aging. These data, when analyzed together with previous studies $(4,5,9)$ indicate that there are two major components to the insulin resistance of aging. First, there is a decrease in the total capacity of glucose utilization, although each of the transport/metabolic units functions normally. Second, evidence exists that insulin action is abnormal in aging. The evidence for abnormal insulin action is that basal glucose transport is normal but that the effectiveness of insulin in stimulating transport (fold increase) is decreased. In addition, the in vivo insulin dose-response curves are shifted right-ward in the face of normal insulin-binding, indicating a postbinding defect in the insulin action system.

\section{Acknowledgments}

We are grateful to Cleon Tate for his excellent secretarial assistance in preparing this manuscript.

This work was supported by funds from the Medical Research Service of the Veterans Administration Medical Center and by grant AM33649 from the National Institutes of Arthritis, Metabolism, and Digestive Diseases of the National Institutes of Health. Dr. Fink was a recipient of a Postdoctoral Fellowship from the Juvenile Diabetes Foundation during the course of these studies. Dr. Fink is currently a recipient of a Research Associate Career Development Award from the Veterans Administration.

\section{References}

1. Davidson, M. B. 1979. The effect of aging on carbohydrate metabolism: a review of the English literature and a practical approach to the diagnosis of diabetes mellitus in the elderly. Metab. Clin. Exp. 8: 688-705.

2. Himsworth, H. P., and R. B. Kerr. 1942. Age and insulin sensitivity. Clin. Soc. 4:153-157.

3. Defronzo, R. A. 1979. Glucose intolerance and aging. Evidence for tissue insensitivity to insulin. Diabetes. 29:1095-1101.

4. Fink, R. I., O. G. Kolterman, J. Griffin, and J. M. Olefsky. 1983. Mechanisms of insulin resistance in aging. J. Clin. Invest. 71:1523-1535.

5. Rowe, J. W., K. L. Minaker, J. A. Palotta, and J. S. Flier. 1983. Characterization of the insulin resistance of aging. J. Clin. Invest. 71: 1581-1587.

6. Jackson, R. A., P. M. Blix, J. A. Matthews, J. B. Hamling, B. M. Din, D. C. Brown, J. Belin, A. H. Rubenstein, and J. D. N. Nabarro. 1982. Influence of aging on glucose homeostasis. J. Clin. Endocrinol. Metab. 55:840-848.

7. Fink, R. I., O. G. Kolterman, M. Kao, and J. M. Olefsky. 1984. The role of the glucose transport system in the postreceptor defect in insulin action associated with human aging. J. Clin. Endocrinol. Metab. 58:721-724.

8. Pagano, G., M. Cassader, P. Cavallo-Perin, A. Bruno, P. Masciola, A. Ozzello, A. Dall'Omo, and A. Foco. 1984. Insulin resistance in the aged. A quantitative evaluation of in vivo insulin sensitivity and in vitro glucose transport. Metabolism. 33:976-981.

9. Boliner, J., J. Ostman, and P. Arner. 1983. Influence of aging on insulin receptor binding and metabolic effects of insulin on human adipose tissue. Diabetes. 32:959-964.

10. National Diabetes Data Group. 1979. Classification and diagnosis of diabetes mellitus and other categories of glucose intolerance. Diabetes. 28:1039-1057.

11. Defronzo, R. A., J. D. Tobin, and R. Andres. 1979. Glucose clamp technique: a method for quantifying insulin secretion and resistance. Am. J. Physiol. 234(3):E214-223.

12. Olefsky, J. M., P. Jen, and G. M. Reaven. 1974. Insulin binding to isolated human adipocytes. Diabetes. 23:565-571.

13. Kashiwagi, A., and J. E. Foley. 1982. Opposite effects of beta adrenergic agonist and phosphodiesterase inhibitors on glucose transport in isolated human adipocytes: isoproterenal increases Vmax and IBMX increases Ks. Biochem. Biophys. Res. Commun. 107:1151-1157.

14. Whitesell, R. R., and J. Gliemann. 1979. Kinetic parameters of transport of 3-O-methyl glucose and glucose in adipocytes. J. Biol. Chem. 254:5276-5283.

15. Hirsch, J., and E. Gallian. 1968. Methods for the determination of adipose cell size in man and animals. J. Lipid. Res. 9:110-119.

16. DiGirolamo, M., S. Medlinger, and J. W. Fertig. 1971. A simple method to determine fat cell size and number in four mammalian species. Am. J. Physiol. 221:850-858.

17. Desbuquois, B., and A. D. Aurbach. 1971. Use of polyethylene 
glycol to separate free and antibody-bound peptide hormones in radioimmunoassays. J. Clin. Endocrinol. Metab. 33:732-738.

18. Faber, O. K., C. Binder, J. Markussen, L. G. Heding, V. K. Naithani, H. Kuzuya, P. Blix, D. L. Horwitz, and A. H. Rubenstein. 1978. Characterization of seven C-peptide antisera. Diabetes. 27:(Suppl 1):170-177.

19. Hansen, I. L., P. E. Cryer, and R. A. Rizza. 1985. Comparison of insulin-mediated and glucose-mediated glucose disposal in patients with insulin-dependent diabetes mellitus and in nondiabetic subjects. Diabetes. 34:751-755.

20. Gottesman, I., L. Mandarino, C. Verdonk, R. Rizza, and J. Gerick. 1982. Insulin increases the maximum velocity for glucose uptake without altering the Michaelis constant in man. Evidence that insulin increases glucose uptake merely by providing additional transport sites. J. Clin. Invest. 70:1310-1314.

21. Kono, T., F. W. Robinson, T. L. Blevins, and O. Ezaki. 1982. Evidence that translocation of the glucose transport activity is the major mechanism of insulin action on glucose transport in fat cells. J. Biol. Chem. 257:10942-10947.

22. Cushman, S. W., and L. J. Wardzala. 1980. Potential mechanisms of insulin action on glucose transport in the isolated rat adipose cell. Apparent translocation of intracellular transport systems of the plasma membrane. J. Biol. Chem. 255:4758-4762.

23. Chen, M., R. N. Bergman, G. Pacini, and D. Porte. 1985. Pathogenesis of age-related glucose intolerance in man: insulin resistance and decreased B-cell function. J. Clin. Endocrinol. Metab. 60:13-20.

24. Fink, R. I., R. R. Revers, O. G. Kolterman, and J. M. Olefsky. 1985. The metabolic clearance of insulin and the feedback inhibition of insulin secretion are altered with aging. Diabetes. 34:275-280.

25. Minaker, K. L., J. W. Rowe, J. Palotta, and D. Sparrow. 1982. Clearance of insulin: influence of steady-state insulin level and age. $\mathrm{Di}$ abetes. 31:132-135.

26. Reaven, G. M., M. S. Greenfield, C. E. Mondon, M. Rosenthal, D. Wright, and E. P. Reaven. 1982. Does insulin removal rate from plasma decline with age? Diabetes. 31:670-673.
27. Bergman, R. N., M. Ader, D. T. Finegood, and G. Pacini. 1984. Extrapancreatic effect of somatostatin infusion to increase glucose clearance. Am. J. Physiol. 247:E370-E379.

28. Rizza, R., C. Verdonk, J. Miles, F. J. Service, and J. Gerich. 1979. Effect of intermittent endogenous hyperglucagonemia on glucose homeostasis in normal and diabetic man. J. Clin. Invest. 63:1119-1123.

29. Gerich, J. E., M. Lorenzi, D. M. Bier, E. Tsalkian, V. Schneider, J. Karam, and P. Forsham. 1976. Effects of physiologic levels of glucagon and growth hormone on human carbohydrate and lipid metabolism. $J$. Clin. Invest. 57:875-884.

30. Hom, F. G., and C. J. Goodner. 1984. Insulin dose-response characteristics among individual muscle and adipose tissues measured in the rat in vivo with ${ }^{3}(\mathrm{H}) 2$-deoxyglucose. Diabetes. 33:153-159.

31. Kraegen, E. W., D. E. James, A. B. Jenkins, and D. J. Chisolm. 1985. Dose-response curve for in vivo insulin sensitivity in individual tissues in rat. Am. J. Physiol. 248(Endocrinol. Metab. II):E353-E362.

32. James, D. E., A. B. Jenkins, and E. W. Kraegen. 1985. Heterogeneity of insulin action in individual muscles in vivo: euglycemic clamp studies in rats. Am. J. Physiol. 248(Endocrinol. Metab. II):E567-E574.

33. Baron, A. D., O. G. Kolterman, J. Bell, L. J. Mandarino, and J. M. Olefsky. 1985. Rates of noninsulin-mediated glucose uptake are elevated in type 2 diabetic subjects. J. Clin. Invest. 76:1782-1788.

34. Best, J. D., G. J. Taborsky, J. B. Halter, and D. Porte. 1981. Glucose disposal is not proportional to plasma glucose in man. Diabetes. 30:847-850.

35. Verdonk, C. A., R. A. Rizza, and J. E. Gerich. 1981. Effects of plasma glucose concentration on glucose utilization and glucose clearance in normal man. Diabetes. 30:505-537.

36. DeFronzo, R. A., and E. Ferrannini. 1982. Influence of plasma glucose and insulin concentration on plasma glucose clearance in man. Diabetes. 31:683-688.

37. Doberne, L., M. Greenfield, M. Rosenthal, A. Widstrom, and G. Reaven. 1982. Effects of variations in basal plasma glucose concentration on glucose utilization $(M)$ and metabolic clearance (MCR) rates during insulin clamp studies in patients with non-insulin dependent diabetes mellitus. Diabetes. 31:396-400. 